\title{
The Effect Mechanism of Tie Strength of Supply Networks on Risk Sharing: Based on the Empirical Data of China's Automobile Manufacturing Industry
}

\author{
Lina Ma ${ }^{1, *}$, Min Wan ${ }^{2}$ and Yushen $\mathrm{Du}^{1}$ \\ 1 Business School of Jilin University, No. 2699 Qianjin Street, Changchun 130012, China; duys@jlu.edu.cn \\ 2 McCoy School of Business, Texas State University, McCoy Hall \#552, 601 University Drive, San Marcos, \\ TX 78666, USA; minwan@txstate.edu \\ * Correspondence: mln@jlu.edu.cn; Tel.: +86-13943055976
}

Citation: Ma, L.; Wan, M.; Du, Y. The Effect Mechanism of Tie Strength of Supply Networks on Risk Sharing: Based on the Empirical Data of China's Automobile Manufacturing Industry. Sustainability 2021, 13, 4439. https://doi.org/10.3390/su13084439

Academic Editor: Andrea Appolloni

Received: 21 January 2021

Accepted: 7 April 2021

Published: 15 April 2021

Publisher's Note: MDPI stays neutral with regard to jurisdictional claims in published maps and institutional affiliations.

Copyright: (c) 2021 by the authors. Licensee MDPI, Basel, Switzerland. This article is an open access article distributed under the terms and conditions of the Creative Commons Attribution (CC BY) license (https:// creativecommons.org/licenses/by/ $4.0 /)$.

\begin{abstract}
Based on the research perspective of the cooperation risk and opportunistic risk between supply network enterprises, this article investigates the mechanism of how tie strength between manufacturers and suppliers influences risk sharing among enterprises from two dimensions of tie strength: structural strength and relational strength. In particular, we introduce how asymmetry of dependence moderates the relationship between tie strength and risk sharing. We surveyed China's domestic auto OEMs and their first-tier suppliers in China through 260 questionnaires and used a hierarchical regression model as a research method to carry out the empirical analysis and test. We found an inverted U-shaped relationship between tie strength and risk sharing among enterprises, and asymmetry of dependence has a significant negative adjustment function on relational strength of the tie and risk-sharing relationship, while there is no significant adjustment function on the structural strength of it. Our findings suggest that keeping moderate tie strength among enterprises is conducive to achieving risk sharing. Moreover, trust and reciprocity is inhibitory regarding the adjustment effect of asymmetry of the dependence influencing relational strength and risk-sharing relationship. However, the structural strength and risk-sharing relationship are not interfered with by the adjustment function of asymmetry of dependence; that is, structural strength plays a decisive role in risk sharing.
\end{abstract}

Keywords: tie strength; risk sharing; asymmetry of dependence

\section{Introduction}

The fundamental motivation of human behavior lies in reducing uncertainty [1]. Besides maximizing profit, how to cope with risk and uncertainties to gain expected profit is a focused issue in supply networks management [2]. Supply failure or delay caused by supply uncertainties is an important source of the risks and uncertainties of supply networks, seriously affecting the implementation of supple chain integration strategy [3]. Under the background of the rapid development of outsourcing, globalization and information technology, the interdependence of resources, along with information and technology among enterprises in the upstream supply network, have increasingly stimulated cooperation. On the contrary, not only does the difference exist between interests and business objectives of member enterprises, so do the conflicts present between the goals and interests of individual enterprises and the overall goals and interests of cooperative enterprises and supply networks. It is evident that opportunistic behaviors and adaptive problems constitute a crucial contracting barrier [4], giving rise to the supply uncertainties of raw materials, products and services of supply networks. Existing literature emphasizes the risk-sharing mechanism of cost-sharing and pooling-of-interest formed by prior contracts among subjects, through stimulating the effort level and coordinating supply chains to reduce or eliminate risks and uncertainties [5]. In the context of competition and cooperation 
among enterprises, the design and execution of contracts affect the depth of cooperation and the efficiency of risk sharing [6]. More importantly, the bounded rationality of the trading subject that causes incomplete contracts is an important factor, leading to cooperation risks and opportunistic behaviors. In order to cover the shortage of formal contracts, establishing relationship governance mechanisms through a series of relational contracts among enterprises is effective to promote the fulfillment of cooperation obligation and commitment to reduce cooperation risks and curb opportunistic behaviors [7].

As a significant mechanism of the cooperation of supply networks, risk sharing optimizes resource allocation between upstream and downstream enterprises [8], changes risk distribution of supply networks [9], stimulates the enterprise effort level [10], and reduces or eliminates risks and uncertainties through cooperation. Existing literature points out that tie strength, an essential dimension of relation embedded features [11] plays a significant role in rational and effective risk-sharing mechanism [12]. However, in the supply network contained by manufactures and suppliers, the current research lacks a clear understanding of how to operate the risk-sharing mechanism effectively and act on risk sharing by connecting manufacturers and suppliers. The existing studies mostly discuss the mechanism of tie strength from the perspective of technological innovation and corporate performance. A weak tie represents a loose, sparse cooperative relationship and plays a role as information bridge, which is beneficial for enterprises to understand market information and technological development trends $[13,14]$. Through long-term trading and interaction, a strong tie represents a cooperative relationship based on trust and reciprocity among supply chain companies, and it is conducive to reducing transaction cost and promoting optimize allocation and the combination of existing and undeveloped resources [15]. However, in the manufacturer-supplier connection relationship, the weak tie and the strong tie account for only a small share while market transaction tie takes the largest proportion. A large number of products, services, etc. required by enterprises are exchanged through a short-term, loose market transaction tie [16]. Additionally, when the embeddedness reaches a certain threshold in the supply network, enterprises will rely excessively on a strong tie, exaggerating trust among enterprises, reciprocal commitments and information sharing relationships [17]. This research defines the connection relationship among enterprises as an over-embedded tie. Diverse embedding intensity of social relationship will lead to different trading features of tie strength among enterprises. Network theory suggests that the embeddedness changes economic behaviors and motivation of the business entity, allowing enterprises to deviate from a narrow self-interest motive and develop a long-term relationship of trust and reciprocity. On the basis of existing theoretical arguments and empirical findings, this paper discusses the status and features of risk sharing under different tie strength from the perspective of bilateral ties between manufactures and suppliers in tie strength and analyzes the mechanism of tie strength on risk sharing.

According to the resource dependence theory, collaboration between enterprises is the strategic behavior of the entity for the purpose of obtaining external resources which constitute the dependence of the entity on an external environment (suppliers, manufacturers, customers, etc.). When the asymmetry of dependence occurs, different companies will have different relative powers. Enterprises with less dependence may use their power to exert influence on the other party [18]. Therefore, what tie strength measures is the strength of cohesion and relationship between both trading parties while asymmetry of dependence represents the degree of balance of the connections between companies. Both reflect various dimensions of a relationship between companies. Under the given tie strength, relative dependence among enterprises may have heterogeneity. Hence, the asymmetry of dependence is a critical element influencing the connection among enterprises. On the foundation of analyzing the mechanism of tie strength on risk sharing, this article introduces the asymmetry of dependence as a moderator into the hypothetical relation model of tie strength and risk sharing, investigating the mechanism of the interaction between asymmetry of dependence and tie strength on risk sharing. 


\section{The Theoretical Analysis and Research Hypothesis}

Risk and uncertainty are important driving factors of supply chain collaboration [19]. Under the assumption of complete rationality, risk sharing is a static distribution process of cost sharing and profit sharing when establishing a transaction relationship, and enterprises will define the risk sharing ratio and rights and obligations by means of contract design. Conversely, under the condition that the entity has limited rationality, enterprises can neither fully identify risks and uncertainties in the operation and transaction process, nor clearly define the right and responsibility under various probabilistic states in the contract, leading incomplete contracts to leave space for opportunistic behaviors. Accordingly, under the condition of risks and uncertainties, the reasonable and effective risk sharing among enterprises, a dynamic and complex process, depends not only on clear terms and cooperation procedures through formal contracts, but also on mutual cooperation based on trust and reciprocity in the transaction process. Based on the above analysis and the necessity of the research, this paper defines the tie strength, the strength of upstream and downstream enterprise connection relationships, from two dimensions-structural strength and relational strength $[20,21]$. In the practice of a supply network, the workflow and interface formed by manufacturers and suppliers through long-term transactions constitute the rules and norms of inter-firm interaction [22,23], which is conducive to the transmission of information and the joint solution of problems [24]. The operation interface between organizations, which acts as the contact point for collaboration between supply networks, plays an important supporting role in risk sharing. Structural strength is used to describe the position of supply chain companies in the supply chain network and the number and quality of connected member companies [25]. This paper defines the structural strength of the tie as the frequency of communication and delivery between upstream and downstream enterprises, the degree of tightness of cooperation, the multiplicity, etc., which reflects the effectiveness of the inter-firm transaction interface and the efficiency of the transaction behavior in the supply network [26]. The higher the risk and uncertainty, the more significant the promoting impact of trust on collaboration among enterprises [27]. Therefore, trust, reciprocity and other factors constitute the basis of the effective operation of the risk-sharing mechanism [28]. Trust and reciprocity are the key indices to measure the relational strength of the tie [29], so the relational strength is an important variable to affect the risk sharing and reflect the motivation of resource exchange and collaboration between the two sides.

The varying degree of embeddedness enables the intensity of mutual trust, information sharing, and joint resolution to be different [30]. The strong tie formed by long-term continuous transactions among enterprises has a basis of trust [21], and has characteristics of high structural strength and high relational strength when reciprocal exchange and cooperation in frequent communication and transactions occur [31]. At the same time, enterprises also tend to seek new resources widely, such as acquiring new information and new technologies by the weak tie or establishing short-term and medium-term market transaction tie by competitive bidding or other forms to obtain the necessary resources. There is no need for enterprises with market transaction ties and weak ties to build a close relationship or even a complex and formal contract or cooperation mechanism. Hence, it's hard for the short-term, competitive market transaction tie to form trust and reciprocity. As a result, market transaction tie has characteristics of low structural strength and low relational strength. The over-embeddedness of social relationships by enterprises leads enterprises to overly rely on a strong tie [14], and exaggerate the trust, reciprocal commitments and information allocation relationships among enterprises. The over-embedded tie has characteristics of exorbitant structural strength and exorbitant relational strength. In the supply network, the tie strength not only reflects the nature of different types of connection relationships, but also reflects the flow mode of information and resources of both parties, having a restrictive function on execution of contracts and risk sharing among manufacturers and suppliers. Among the four types of contact (i.e., strong tie, weak tie, market transaction tie, and over-embedded tie), there is only a small amount 
of or no tie among enterprises with a weak tie, which has little capability of forming a virtual risk-sharing relationship. Therefore, from two dimensions-structural strength and relational strength - this paper focuses on the characteristics of the three types of tie strength (market transaction tie, strong tie, and over-embedded tie) and the mechanism on risk sharing among manufacturers and suppliers.

\subsection{The Structural Strength of Tie and Risk Sharing}

Through competitive bidding, multi-sourcing, and dual-source procurements, manufacturers form a market transaction tie with multiple suppliers by employing short-term and medium-term contracts, which lead to a variety of alternative connection paths between the manufacturer and the supplier base. Manufacturers only select and change the supplier based on quotation, supply, etc., and market transaction tie has short-lived, flexible characteristics. Therefore, in the market transaction tie, which depends on the stylized transaction process, enterprises pay attention to the stable flow of products and raw materials instead of the development of long-term transaction tie between enterprises, according to the contract terms. Hence, for the purpose of profiting from short-term transactions, a stylized transaction process cannot promote frequent communication and close cooperation between enterprises, which is not conducive to the formation of a risk-sharing mechanism among enterprises.

By contrast, through long-term transactions and interactions, manufacturers and suppliers with strong tie form operational interface and resource management system between enterprises. Complex, highly integrated processes facilitate the joint planning and control of resources [32], reducing ambiguity and improving efficiency [33]. The close relationship between upstream and downstream enterprises in the supply chain can encourage suppliers or customers to have the motivation to share knowledge and information with enterprises [34]. Close and stable cooperative relations make it easier for companies to obtain customer information and technical information that are difficult to obtain by traditional methods [35]. Frequent communication, close interaction, and multi-project cooperation allow the two parties to obtain more cooperation opportunities. The system and institutional arrangement of cooperation can promote the combination and optimal allocation of resources, realizing the value and rent included in the resource combination through inter-enterprise operating activities [22]. Structural strength provides a context that aids adaptive collaborative behavior by companies that are part of the supply network [36]. Therefore, the structural strength of strong tie plays a vital role on the risk sharing among enterprises, allowing both parties to be more likely to identify and use potentially valuable resources, change the risk distribution of supply network, suppress cooperation risks and opportunistic risks, and achieve effective and reasonable risk sharing.

In an over-embedded tie, the proprietary language and workflow which result from long-term interactions between manufacturers and suppliers, and the capital costs of transaction-specific investment, cause the profit that can only be realized if the transaction relationship persists. Excessively frequent contacts have formed high-level ties and too tight relationships between companies [17], restricting the selection of trading partners and changes in trading behaviors and forming a company contracting relationship. As transactions in networks are limited to specific trading partners, the homogeneity of the network hinders the inflow of new technologies and new information [37], reducing approaches of obtaining non-redundant information and new opportunities. In this way, the relatively closed and redundant information circle of the supply network causes the locking of the enterprise's functions and perceptions [38], leading to the loss of cooperation adaptability and flexibility [39]. Therefore, excessively high structural strength in an over-embedded tie leads to a decrease in the openness and flexibility of the cooperative relationship, and it is difficult to form effective risk sharing among enterprises. Based on the arguments above, we propose that: 
Hypothesis 1. There is an inverted U-shaped nonlinear relationship between the structural strength of the tie and the risk sharing between manufacturers and suppliers.

\subsection{The Relational Strength of Tie and Risk Allocation}

The transient and flexible competition and cooperation relationship in the market transaction tie makes it difficult for both parties to form a high level of trust and reciprocity through limited transaction history. On one hand, in the transaction process, the lower relational strength leads to the formation of false expectation and misunderstanding of the other party's intentions, resulting in unnecessary suspicion and opportunistic behaviors and hindering the company's risk-sharing behaviors. On the other hand, due to a low degree of trust existing among enterprises, both parties tend to be risk aversive and vigilance with less willingness of sharing risks [40]. Therefore, in market transactions, the lower relational strength is not beneficial for the formation of effective risk-sharing mechanism among enterprises.

Trust, friendship, respect, and reciprocity among enterprises are crucial for risk sharing [41]. With a strong tie, companies have formed a high degree of trust and reciprocity through a good transaction history, which is profitable to the cooperative parties on more efficient resource allocation [42], the transfer of complex and tacit knowledge [43], raising the willingness of the subject to share risks [40], and solving problems together. Relational strength shifts a partner's attitude from selfishness to trust and reduces the risk of opportunistic behavior during the cooperation [44,45]. In addition, trust and reciprocity can stimulate the effort level of the entity, increase the willingness of the company to cooperate outside the contract terms, and reduce the transaction costs of negotiation and supervision between the parties [46,47]. Finally, trust and the willingness of the entity to share risks are closely related [48]. A high level of trust increases the willingness of companies to share risks and mitigate conflicts and contradiction. Therefore, a strong tie based on trust and reciprocity can prompt enterprises to integrate and use resources for creative cooperation [49], through which companies jointly solve problems and disputes, reduce transaction costs, and form effective risk-sharing mechanisms. As a result, in a strong tie, the stability and efficiency of both parties' risk sharing are higher than the risk-sharing mechanism under the market transaction tie.

In the process of long-term historical transactions, enterprises establish social relationship through mutual communication, mutual trust and shared values [50]. When the embeddedness of social relations exceeds a certain threshold, enterprises excessively rely on strong tie, overstating trust, reciprocity and information sharing relationship [51]. In the over-embedded tie, the entity holds the belief that the partner will take actions that have positive effects on them [52,53], and exhibit less supervision of improper conduct. In this way, due to the reduced supervision level, enterprises cannot objectively understand the recession of performance and detection of deceit. Under the cover of social relations, the other party may form a systematic deception method [54], such as slowing down the information transfer process, affecting the exchange of complex knowledge and resources [55], or increasing the risk of cooperation and opportunism. Trust is closely linked to the willingness of risk sharing, and when one side overly trusts the other, it essentially gives the other party opportunities to change the motivation of opportunistic behaviors to action [56]. Opportunism would increase if good business practices to foster trust as recommended are not adopted as stipulated in the listed factors and vice versa [57]. Secondly, the strong reciprocity mode enables the enterprise to undertake additional and unnecessary obligations, promising the non-optimal allocation of resources and risk-sharing ratio [58]. In this case, a high level of social capital in the over-embedded tie causes the high relational strength of tie, making the cooperation depart from the risk-sharing principle based on the efficiency and fairness and increasing the cooperation risk and opportunism risk, which is not conducive to forming a reasonable and effective risk sharing. Hence, this paper proposes Hypothesis 2. 
Hypothesis 2. There is an inverted $U$-shaped nonlinear relationship between the relational strength of the tie and the risk sharing between manufacturers and suppliers.

\subsection{Adjustment Function of the Asymmetry of Dependence}

In practice, the asymmetry of dependence is prevalent in the connection relationships between manufacturers and suppliers, and the interdependence of symmetry is difficult to achieve. Especially in developing countries, as the majority of enterprises in these countries are more dependent on the other members in supply chains, though they contribute greatly to their economies [59]. This is because specific assets are asymmetric. For example, if a supplier wants to establish a trading relationship with a manufacturer, the supplier must invest in specific assets to meet the other party's technical requirements and governance standards, and the investment proportion of specific assets is usually higher than that of the manufacturer. This causes the initial cost and the exit cost of the supplier to be significantly higher than the manufacturer, and the relative dependence on the manufacturer to be relatively high. Another reason is that information is asymmetric. The different resource positions of manufacturers and suppliers in the supply chain determine the asymmetry of information among enterprises. Generally speaking, manufacturers are more likely to obtain demand information in the downstream market while suppliers have more supply information of intermediate products and raw materials. when establishing and continuing transaction relationships, enterprises form an expectation of future events based on information, making trading decisions. The expectation bias produced by the asymmetry of dependence directly affects the trust and reciprocity between manufacturers and suppliers, as well as the depth and scope of resource and information exchange and integration [60], ultimately affecting the risk sharing among enterprises. Therefore, this study introduces the asymmetry of dependence as an important regulatory variable from the two dimensions of tie strength (i.e., relational strength and structural strength), and analyze the effect mechanism of the interaction between the asymmetry of dependence and tie strength on risk sharing.

\section{(1) Structural strength}

In the supply network, companies break the restriction of borders by establishing cooperative relationships and obtaining external resources more effectively. In this process, based on the characteristics of their resource and the dependence on external resources, companies integrate their complementary resources by developing their relationships with other member companies [61]. Mitsuhashi and Greve [62] believe that in the case of mutual dependence symmetry, if the resources of both parties have a high degree of complementarity and compatibility, companies tend to configure and exchange resources through collaborative cooperation. However, in the case of the asymmetry of dependence, the dominant party who has mastered key resources will anticipate less reception of transaction payments, thereby controlling the weaker parties and taking opportunistic behaviors to maintain their power status; the weak parties will be forced by the other party's power advantage to accept requirements in the process of cooperation, being in a passive position of relying on superiority and being easily controlled [63]. Moreover, the higher the level of asymmetry, the greater the possibility of opportunism [64]. In market transaction tie, the knowledge system with low complementarity between enterprises and highly inconsistence results in the inability of both parties to effectively identify each other's useful resources to optimize the resource mix [65], and stylized inter-enterprise transaction processes and interfaces also lack active promotion of the exchange, absorption, and assimilation of resources (knowledge, information, etc.) This will greatly reduce the opportunities for both parties to form a resource portfolio, hinder interaction and operational efficiency, and reduce the potency for risk sharing between both parties.

Although companies with strong tie can rely on complex and highly integrated workflows and interfaces to achieve the transfer and integration of resources, in the case of the asymmetry of dependence, the dominant parties will have a negative attitude toward 
resource exchange and transfer due to resource spillover effects [63]. Compared with resource-dominant parties, disadvantaged parties will seek the exchange and optimization of resources to reconstruct the dependencies among enterprises. This behavior leads the dominant parties to refuse to form a long-term alliance with the disadvantaged in order to maintain its dominant position. The disadvantaged parties also think that they are unable to benefit from the transaction in the future, but they will form excessive dependence on specific trading partners and also hesitate to establish cooperation with the dominant parties [66]. In this case, the frequency of communication, the transaction between enterprises, and the tightness and multiplicity of cooperation are all degraded, which is not conducive to the formation of risk-sharing cooperative behavior among enterprises. Furthermore, compared with resource-disadvantaged parties, the incentives for sharing and transmitting information by the dominant parties are weak [67], resulting in the failure of forming effective information flow in the supply network and reducing the frequency and efficiency of enterprise communications, which is not conducive to effective negotiation and joint solution of problems through information exchange.

As a result, enterprises have not been able to make full use of collaborative operational processes and interfaces and cannot achieve communication under multiple cooperation. Therefore, in the case of the asymmetry of dependence, it is difficult for enterprises with strong tie to form mutually satisfactory exchange relationships, which is not conducive to effective risk sharing.

In the over-embedded tie, the lock of the relationship leads both parties to relying on each other's enterprises to provide key resources and information, and the long-term repeated cooperation forms the rigidity of the relations between the enterprises. The difference in relative dependence leads to the unequal power of corporate subjects. Under such condition, the dominant parties will not have the same incentives as the disadvantaged parties to exchange information and exchange resources. The resulting barriers of exchanging information result in the lack of domain consensus for both parties, increasing the frequency of conflicting behaviors between both parties [68] and constituting an important obstacle to successful negotiation. Secondly, during the transaction process, companies with different powers have different interest demands and goals, for which the dominant side tends to reach an agreement that is beneficial to itself while the weaker side hopes to obtain reasonable benefits through negotiation. This leads to a complicated process of bargaining, so that both parties have more high transaction costs [69,70].Therefore, in the case of the asymmetry of dependence, although companies rely on the cooperation process and interface formed by long-term historical transactions to achieve a stable flow of resources, unequal power hinders effective negotiation and jointly solving problems among enterprises, which is detrimental to the resolution of conflicts and reduction of the transaction frequency [67]. In the over-embedded tie, because the two parties cannot cooperate constructively, the ability of the enterprise to respond to risks and uncertainties is reduced, which is difficult to form effective risk sharing. Therefore, this paper proposes Hypothesis 3.

Hypothesis 3 . The inverted $U$-shaped relationship between structural strength and risk sharing is stronger when the level of the asymmetry of dependence between manufacturers and suppliers is high.

\section{(2) Relational strength}

Equity is the subject's psychological perception of whether decisions, processes, and outcomes are reasonable and fair. Fairness perception affects trust and reciprocity between subjects [71], constituting the motivation of subjective risk-sharing behavior, which then influences the dynamics of transactions [72]. In the supply network, the degree of resource dependence and the importance of resources play a decisive role in the distribution of power among enterprises. Compared with the dominant side, the disadvantaged side is in a vulnerable position and more sensitive to fair payment. In the market transaction 
tie, the connection relationship between enterprises has an indifferent and loose characteristic, leading to the fact that the companies do not have the expectation of continuous trading. Both parties are risk-averse and will always be vigilant in cooperation risks and opportunistic behaviors in the process of cooperation [73]. The asymmetry of dependence has further intensified this tendency, resulting in enterprises being more sensitive to the fairness perception of cooperation process and income distribution. At the same time, the weak trust and reciprocity between enterprises have been greatly reduced, further inhibiting both parties' risk sharing and motivation. Therefore, it is difficult for enterprises with market-related transactions to form an effective risk-sharing mechanism.

Due to the asymmetry of information, even in a strong tie, companies do not have the ability to accurately estimate fairness. In this way, companies will not be able to perceive the deviations of partners from contracts and reciprocity obligations, and then supervise and verify information and hidden misconduct. When the asymmetry of dependence exists, the dominant side has the advantages of resources and power. The disadvantaged side will realize that they are vulnerable to control and unable to counterattack. Therefore, the disadvantaged side will be more likely to have the perception of the other party taking opportunistic behaviors [74]. In order to protect one's own interests, the disadvantaged side will require greater decision participation and control in the decision process and distribution results, which will result in both parties tangling the quasi-rent bargaining and increasing transaction costs. Therefore, the asymmetry of dependence will weaken trust and reciprocity among supply network enterprises, increase the conflict level among manufacturers and suppliers, and reduce the level and efficiency of risk sharing among enterprises.

In the over-embedded tie, enterprises excessively exaggerate the relationship of trust, reciprocity, and information sharing, resulting in social rationality of both parties of the transaction surpassing economic rationality and restricting the transaction behaviors of the subject of the enterprise. Over-embeddedness of social relationships leads enterprises to excessively exaggerate their trust and make irrational commitments, reduce supervision of misconduct and assume additional and unnecessary obligations. This provides an opportunity for cooperative companies to take opportunistic behaviors to invade the interests of the other company $[54,69]$. At the same time, under the over-embedded tie, the dominant side also relies on the disadvantaged side which can provide key resources, due to which the disadvantaged also has power [67], and may take opportunistic behaviors for self-interest motives. In this case, the asymmetry of dependence will lead companies to be more sensitive and nervous to distribution fairness and process fairness [75] and to be easy to perceive each other's opportunistic behaviors and thus raise the conflict level between both parties. As a result, in over-embedded tie, the asymmetry of dependence reduces trust and reciprocity among enterprises [76], further changing the behavioral tendency of corporate entities, and suppressing the effectiveness of risk-sharing mechanisms among enterprises. This paper proposes the following assumptions.

Hypothesis 4 . The inverted $U$-shaped relationship between relational strength and risk sharing is stronger when the level of the asymmetry of dependence between manufacturers and suppliers is high.

Based on the above hypotheses, this study proposes the following Figure 1: 


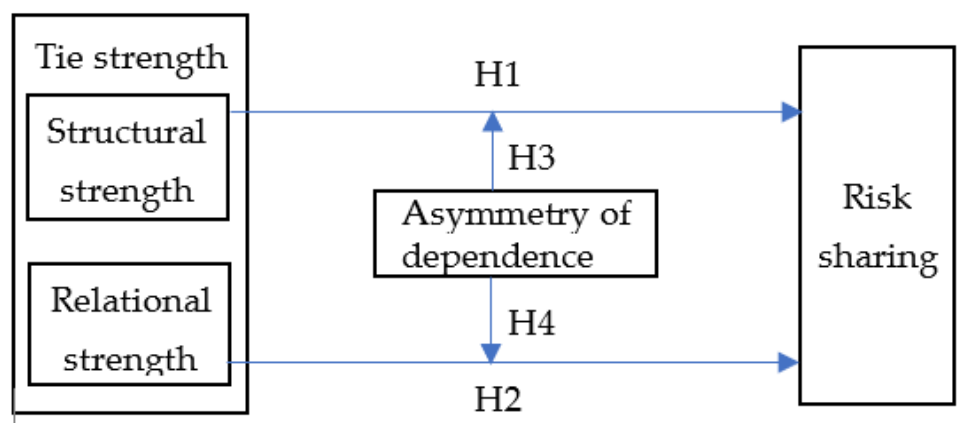

Figure 1. The conceptual framework.

\section{Research Design}

\subsection{Data Source and Sample Selection}

We surveyed China's domestic auto OEMs and their first-tier suppliers in China between July 2018 and December 2018. A total of 260 questionnaires were distributed through e-mails and telephone interviews. Under group members' communication with the surveyed company on site or by phone, the surveyed company's procurement or related person in charge filled the questionnaire. Due to the large number of first-tier suppliers of vehicle manufacturers, the procurement managers could not provide feedback one by one. In order to comprehensively collect the evaluation data of the risk-sharing relationship between manufacturers and suppliers, 230 questionnaires were sent to the first-tier supplier companies, including 166 retrieved valid questionnaires, meaning that the effective recovery rate was $72 \% ; 30$ questionnaires were issued to vehicle manufacturers and its purchasing person in charge and the research group mutually agreed to select 30 suppliers in which its purchasing director will fill in questionnaires on the risk-sharing relationship between the two parties. These 30 questionnaires were all recovered and the effective recovery rate was $100 \%$.

For survey biases that may exist through questionnaire surveys, this paper conducted non-response bias $t$-test on the number of employees, annual sales revenue and relationship duration between enterprises that give feedback and those that do not (number of employees: $\mathrm{t}=2.46, p=0.17$; annual sales revenue: $\mathrm{t}=1.51, p=0.19$; contact duration $\mathrm{t}=-1.43, p=0.11)$. The results were not significant $(p>0.10)$, indicating that there was no significant difference between the samples, and the non-response bias had little effect on subsequent studies. At the same time, in order to test the common method bias, this paper used single factor test to estimate the severity of the common method bias and the test results showed that the most important single factor explained $18.35 \%$ of the total variance, which means that common method bias is not a main issue in this study.

\subsection{Variable Measurement and Inspection}

This survey questionnaire includes 4 indicators: risk sharing, relational strength, structural strength and relative dependence. There were a total of 28 survey items in the survey, and we used the Likert 6-point scale ( $1=$ completely disagree to $6=$ fully agree). This paper selects a six-point scale to eliminate the median and improve the surface validity of the metric. This survey requires the participants to make judgments on the risk-sharing situation of the two parties, the transactions of both parties and the frequency of communication based on their purchasing and risk management experience. In order to ensure the initial reliability and content validity, this paper constructs 28 survey items to measure the corresponding indicator variables pre-tested by scholars and practitioners to ensure the validity and credibility of the questionnaire design. At the same time, through the pre-test of the questionnaires of the purchasing managers and relevant managers of the companies in question, the survey items are continuously adjusted and improved to ensure the validity of the samples in the formal survey. In this paper, the questionnaire data samples of 30 tier-one supplier relationships feedback from vehicle manufacturers are 
cross-tested with the questionnaire data feedback from the 30 suppliers, showing that there is no significant difference in the feedback values of the two questionnaires, reflecting high correlation $(t=-1.54$; correlation coefficient $=0.82)$. Therefore, the following empirical part takes the 166 questionnaire data feedback from the supplier companies as a sample to analyze the mechanism of the tie strength on risk sharing. The descriptive statistics of the sample are shown in Appendix A.

(1) Dependent variable-risk sharing. Referring to the research results of existing literature on risk sharing, this paper combines the characteristics of manufacturer supplier relationships in the supply chain, selecting key factors for questionnaire design. It should be pointed out that respondents' perceptions (subjectivity) regarding risk sharing is not an objective measurement, but a subjective one, whose maturity still needs to be further verified. The risk-sharing scale includes three aspects: rationality, matching, and effectiveness [12]. According to the theory of risk efficiency, one of the principles of risk sharing is that the party who has the ability to control the risk should bear the risk. Then the rationality is used to measure whether the risk sharing of the enterprise follows this principle. Because both parties have heterogeneous resources endowments and bargaining powers, the risks shared by the disadvantaged may not match the obtained gains, suffering losses in the transactions, and the parties with higher bargaining powers obtain all the surpluses. So the measure of risk sharing and gains by the companies is measured by the degree of matching. Whether the manufacturer-supplier partnership has improved the ability and effectiveness of the two sides to jointly negotiate and solve problems, and whether it reduces the cost of risk management and the total economic cost of risk sharing, reflect the effectiveness of the risk-sharing relationship. In this paper, an exploratory factor analysis of the risk-sharing scale is performed, showing that the scale Cronbach's value is 0.82 , which has good reliability, the variance contribution rate is $67.29 \%$, and the KMO value is 0.795 , meaning that the data is suitable for factor analysis (as shown in Table 1).

Table 1. Exploratory Factor Analysis of Risk Sharing.

\begin{tabular}{ccccc}
\hline Measured Variables & Brief Description of the Scale Item & Factor Loading & Cronbach's $\alpha$ & KMO \\
\cline { 1 - 3 } RS1 rationality & Follow the principle of being able to take risks & 0.63 & 0.82 \\
\cline { 1 - 3 } RS2 matching & The matching of risks and benefits & 0.71 & \\
\cline { 1 - 3 } RS3 effectiveness & Work together to solve problems and reduce trading risks & 0.76 & \\
\hline
\end{tabular}

Note: the public factor extraction method is the main component analysis, and the cumulative variance contribution rate is $67.29 \%$. RS refers "risk sharing" and is used for questionnaire item code.

(2) Independent variable-tie strength. This paper measures the tie strength from two dimensions-structural strength and relational strength. The measurement of structural strength uses the relevant indicators of the strengths of existing research linkage relationships: tie frequency, cooperative intimacy, and multiplicity [24]. The tie frequency between manufacturers and suppliers is measured by the number of contacts between companies in different ways (telephone contact, written contact, face-to-face communication, delivery); cooperative intimacy refers to the degree of mutual trust and cooperation between the two parties based on a good transaction history. Multiplicity is measured by the scope and number of partnerships (e.g., joint projects, joint research and development, etc.). As for the relational strength of the tie, the questionnaire involves factors such as reciprocity, equal consultation, and trustworthiness of the two parties' cooperative relationships. In this paper, an exploratory factor analysis is performed on the tie strength scale, showing that the Cronbach's $\alpha$ value of the structural strength scale of tie is 0.82 , and the Cronbach's $\alpha$ value of the relational strength scale of tie is 0.79 , which has a good reliability and the cumulative variance contribution rate is $62.17 \%$; the $\mathrm{KMO}$ value of the structural strength scale of tie is 0.657 , and the KMO value of the relational strength scale of tie is 0.719 (as shown in Table 2). All greater than 0.5, indicating that the data is suitable for factor analysis. 
Table 2. Exploratory Factor Analysis of Tie Strength.

\begin{tabular}{|c|c|c|c|c|c|}
\hline \multirow[b]{2}{*}{ Measured Variables } & \multirow{2}{*}{$\begin{array}{l}\text { Brief Description of the } \\
\text { Scale Item }\end{array}$} & \multicolumn{2}{|c|}{ Factor Loading } & \multirow[b]{2}{*}{ Cronbach's $\alpha$} & \multirow[b]{2}{*}{ KMO } \\
\hline & & $\begin{array}{l}\text { Structural } \\
\text { Strength }\end{array}$ & $\begin{array}{l}\text { Relationship } \\
\text { Strength }\end{array}$ & & \\
\hline $\begin{array}{l}\text { TS1 Face-to-face } \\
\text { communication frequency }\end{array}$ & & 0.62 & 0.15 & \multirow{7}{*}{0.82} & \multirow{7}{*}{0.657} \\
\hline $\begin{array}{l}\text { TS2 Telephone contact } \\
\text { frequency }\end{array}$ & & 0.81 & 0.04 & & \\
\hline $\begin{array}{l}\text { TS3 Written contact } \\
\text { frequency }\end{array}$ & & 0.76 & -0.03 & & \\
\hline TS4 Delivery frequency & & 0.51 & -0.07 & & \\
\hline $\begin{array}{l}\text { TS5 Average contact } \\
\text { frequency (past 3-6 months) }\end{array}$ & & 0.83 & -0.18 & & \\
\hline TS6 Degree of compactness & $\begin{array}{l}\text { The degree of trust and } \\
\text { cooperation formed in } \\
\text { historical transactions } \\
\text { is different }\end{array}$ & 0.57 & -0.07 & & \\
\hline TS7 multiplicity & $\begin{array}{l}\text { Number of cooperation } \\
\text { types (such as joint projects } \\
\text { or joint research and } \\
\text { development) }\end{array}$ & 0.69 & 0.2 & & \\
\hline $\begin{array}{l}\text { TS8 Manufacturer's } \\
\text { commitment }\end{array}$ & & 0.09 & 0.79 & \multirow{6}{*}{0.79} & \multirow{6}{*}{0.719} \\
\hline TS9 Supplier commitment & & 0.05 & 0.85 & & \\
\hline TS10 Equal consultation & & -0.07 & 0.69 & & \\
\hline TS11 Degree of reciprocity ${ }^{a}$ & & 0.15 & 0.78 & & \\
\hline TS12 Degree of reciprocity $b$ & & -0.04 & 0.76 & & \\
\hline $\begin{array}{l}\text { TS13 Manufacturer's } \\
\text { dependence degree }\end{array}$ & & 0.1 & 0.81 & & \\
\hline
\end{tabular}

Note: the public factor extraction method is the main component analysis, and the cumulative variance contribution rate is $62.17 \%$. ST refers "strength tie" and is used for questionnaire item code. ${ }^{a}$ : Both parties refrain from making requests that seriously harm the interests of the other party. $^{\mathrm{b}}$ : Deeply appreciate what the other party has done for the company.

(3) Moderator variable- the asymmetry of dependence. This paper only focuses on the degree of the asymmetry of dependence, without considering the direction of dependence. Therefore, in order to measure the degreqe of the asymmetry of dependence between the two parties, the asymmetry of dependence is defined as the difference between manufacturer' and suppliers' relative dependence on each other, $\left|D_{S}-D_{M}\right|[60]$. For the relative dependence of manufacturers and suppliers, this paper only proceeds from the mutually dependent state attributes as a function of the importance of resources and the availability of alternative resources. In terms of setting up questionnaires, referring to the existing research conclusions, there are four aspect: the importance of transactions, the degree of investment in special-purpose assets, transaction concentration, and transaction substitutability measuring the relative dependence of manufacturers and suppliers. Then, the asymmetry of dependence can be measured through taking difference on the relative dependence of manufacturers and suppliers and using the Likert 6-point scale, which is divided into 6 levels from 6 points to 1 point.

This paper conducts exploratory factor analysis, showing that the hidden variables such as the relative dependence degree of supply $D_{S}$ and the manufacturer's relative dependence degree $\mathrm{D}_{\mathrm{M}}$ jointly explain $70 \%$ of the data variation. Three of the 12 items with two-factor load are rejected and then the reliability test is performed on the remaining scales. The results show that the supplier's relative dependence metric Cronbach's $\alpha$ value 
is 0.76 , the manufacturer's relative dependency scale Cronbach's $\alpha$ value is 0.81 , and the cumulative variance contribution rate is $71.59 \%$. After culling, the correlation coefficient between the two scales is $0.146(p<0.01)$, indicating that scales have good discriminant validity (as shown in Table 3).

Table 3. Exploratory Factor Analysis of Asymmetry of Dependence.

\begin{tabular}{|c|c|c|c|c|c|}
\hline Measured Variables & $\begin{array}{l}\text { Brief Description of the } \\
\text { Scale Item }\end{array}$ & \multicolumn{2}{|c|}{ Factor Loading } & Cronbach's $\alpha$ & KMO \\
\hline \multirow{3}{*}{$\begin{array}{l}\mathrm{DM} \\
\text { (Manufacturer's relative } \\
\text { dependence on supplier) }\end{array}$} & $\begin{array}{l}\text { The fluctuation importance of } \\
\text { supplier production on } \\
\text { manufacturer }\end{array}$ & -0.02 & 0.51 & \multirow{3}{*}{0.81} & \multirow{3}{*}{0.653} \\
\hline & Supplier substitution & 0.26 & 0.71 & & \\
\hline & $\begin{array}{l}\text { Manufacturer's dependence on } \\
\text { supplier's products }\end{array}$ & 0.15 & 0.8 & & \\
\hline \multirow{6}{*}{$\begin{array}{c}\text { Ds } \\
\text { (Supplier's relative dependence } \\
\text { on manufacturer) }\end{array}$} & $\begin{array}{c}\text { The proportion of suppliers' } \\
\text { supply in manufacturers' similar } \\
\text { products }\end{array}$ & 0.76 & 0.18 & \multirow{6}{*}{0.76} & \multirow{6}{*}{0.714} \\
\hline & Manufacturer substitution & 0.46 & 0.01 & & \\
\hline & Manufacturer exit costs & 0.87 & -0.05 & & \\
\hline & $\begin{array}{l}\text { Supplier's proprietary investment } \\
\text { (technology) }\end{array}$ & 0.49 & 0.03 & & \\
\hline & $\begin{array}{l}\text { Supplier's proprietary investment } \\
\text { (production equipment or } \\
\text { production line) }\end{array}$ & 0.58 & 0.01 & & \\
\hline & $\begin{array}{l}\text { Supplier labor cost (personnel } \\
\text { training, etc.) }\end{array}$ & 0.51 & 0.03 & & \\
\hline
\end{tabular}

Note: the public factor extraction method is the main component analysis, and the cumulative variance contribution rate is $71.59 \%$.

(4) Control variables. The characteristics of the interviewed companies and the characteristics of the industry they belong to may have false effects on risk sharing affecting the accuracy of the research findings. In order to reduce the impact of false effects, this paper draws on relevant literature, selecting the enterprise scale, the relationship duration and the industry of the supplier enterprise as the control variables. Among them, the enterprise scale is calculated based on annual sales revenue and the natural logarithm of the number of full-time employees, and the relationship duration is the duration of the transaction.

\subsection{Empirical Model}

For the assumptions to be verified, the empirical model of this paper is set to the following form.

$$
\begin{aligned}
& \text { Model 1Y }=\beta_{1} X_{S}+\beta_{2} X_{S}^{2}+\beta_{3} Z+\beta_{4} X_{S} Z+\beta_{5} X_{S}^{2} Z+C_{0} \\
& \text { Model } 2 Y=\beta_{1} X_{R}+\beta_{2} X_{R}^{2}+\beta_{3} Z+\beta_{4} X_{R} Z+\beta_{5} X_{R}^{2} Z+C_{0}
\end{aligned}
$$

Among them, $X_{S}$ and $X_{R}$ in Models 1 and 2 respectively represent the structural strength and the relational strength, and $Z$ represents the asymmetry of dependence. This paper uses a hierarchical regression model as a research method to analyze the linear interaction of the square of tie strength and risk sharing. The dependent variable, risk sharing, the independent variables, structural strength and relational strength, and the moderator variable, the asymmetry of dependence, are continuous variables composed of factor scores which leads this paper to adopting a multivariate linear model for regression analysis. In order to test the regulatory effect of the asymmetry of dependence, this paper also respectively constructs interaction terms that rely on the asymmetry of dependence 
and structural strength $\left(X_{S}\right)$ in the two models, interaction terms that rely on the asymmetry of dependence and squared term $X_{S}^{2}$ of structural strength, interaction terms that rely on the asymmetry of dependence and relational strength $\left(X_{R}\right)$, interaction terms that rely on the asymmetry of dependence and squared term $X_{R}^{2}$ of relational strength, using the hierarchical regression analytical test the curve effect of the independent variable on the risk-sharing $\mathrm{Y}$, and the interaction with the asymmetry of dependence.

\section{Empirical Test and Result Analysis}

Before analyzing the relationship between variables, the paper examines the correlations between the variables, the average, standard deviation and correlation coefficient of each major variable shown in Table 4. Among them, there are significant correlations between the risk sharing and control variables such as trading relationship duration and industry, and the correlation coefficients are 0.23 and 0.21 , respectively. There is a significant positive correlation between risk sharing and structural strength and relational strength. The correlation coefficients are $0.25,0.49$, but there is no significant linear correlation between risk sharing and the asymmetry of dependence. At the same time, there is no significant correlation between enterprise scale and structural strength; there is a significant correlation between the relationship duration and the relational strength, and there is no significant correlation between the relationship duration and the structural strength. In addition, the analysis results of variance inflation factor (VIF) show that the variance inflation factor of a single variable is between 1.09 and 1.66, and the mean value of the variance inflation factor of all variables is 1.336 , less than 2 , so there is no significant multicollinearity.

Table 4. Variables' mean value, variance, VIF and Pearson correlation coefficients.

\begin{tabular}{|c|c|c|c|c|c|c|c|c|c|c|}
\hline Variables & 1 & 2 & 3 & 4 & 5 & 6 & 7 & $\mathbf{M}$ & SD & VIF \\
\hline Enterprise scale & 1 & & & & & & & 2.79 & 0.88 & 1.11 \\
\hline Duration & $0.29 * *$ & 1 & & & & & & 12.7 & 0.33 & 1.09 \\
\hline Industry & -0.11 & -0.14 & 1 & & & & & 2.84 & 0.91 & 1.66 \\
\hline Structural strength & 0.04 & -0.08 & 0.01 & 1 & & & & 4.22 & 0.76 & 1.45 \\
\hline Relational strength & $0.17^{*}$ & $0.37^{* *}$ & 0.14 & $0.17^{*}$ & 1 & & & 4.57 & 0.69 & 1.37 \\
\hline Dependent asymmetry & -0.04 & 0.01 & -0.02 & -0.13 & -0.09 & 1 & & 2.2 & 0.59 & 1.61 \\
\hline Risk sharing & 0.05 & $0.23 *$ & $0.21^{* *}$ & $0.25^{* *}$ & $0.49 * *$ & -0.02 & 1 & 4.06 & 0.81 & - \\
\hline Average VIF & - & - & - & - & - & - & - & - & - & 1.38 \\
\hline
\end{tabular}

Note: $\mathrm{N}=166,{ }^{*}$ and ${ }^{* *}$ indicated that the results were significantly double-tailed at the level of 0.1 and 0.05 .

\subsection{Hypothetical Test}

In order to reduce and eliminate the potential multiple collinearity problems, the mean centralization of variables is studied. Then, this paper performs hierarchical regression analysis on the two models based on six steps. First, the control variables are entered into the model to control the influence of the mixed factors; in the second and third steps, the linear term $X$ and squared term $X^{2}$ of the single dimension of tie strength are entered into the model to test its influence on the explanatory power of the equation; in the fourth and fifth steps, the asymmetry of dependence is entered as the linear independent variable $\mathrm{z}$ and the interaction term $X Z$ of tie strength; the sixth step is to add the squared linear term $\mathrm{X}^{2} \mathrm{Z}$ into the model to test whether the inverted U-shaped relationship between tie strength and risk sharing will change due to the asymmetry of dependence.

The regression analysis results of Model 1 are shown in Table 5. In order to test Hypothesis 1 and to explore the relationship between structural strength and risk sharing, this paper adds control variables in the first step of Model 1 to eliminate the influence of mixed factors. The second step is to add a linear term of structural strength to investigate the main effect of structural strength Table 5 (S2), showing that there is a significant positive 
correlation between risk allocation and structural strength $(0.23, p<0.05)$, meaning that structural strength has a role in risk sharing that will promote as the structural strength increases. However, as mentioned above, only considering the linear relationship between the structural strength of tie and the risk sharing will be one-sided, so this paper adds the squared terms of the structural strength in the third step of the model Table 5 (S3) in which the data show there is a significant inverted U-shaped relationship between the structural strength of tie and the risk sharing. Meanwhile, the overall explanatory power of the model is enhanced with the increase of $R^{2}$. The coefficient of the linear term $X_{S}$ of the structural strength is significantly positive, and the coefficient of the squared term $X_{S}^{2}$ of the structural strength is significantly negative $(-0.29, p<0.01)$, indicating that there is an inverted U-shaped nonlinear trend in risk sharing as the structural strength increases. Hypothesis 1 is verified. However, considering that the increase of $R^{2}$ is not obvious, this result indicates that the explanatory power of the overall explanatory variable for risk sharing is not enough, and there may be more potential explanatory variables that need to be included in the model.

Table 5. Hierarchical Regression Analysis.

\begin{tabular}{|c|c|c|c|c|c|c|}
\hline Variables & S1 & S2 & S3 & S4 & S5 & S6 \\
\hline Enterprise scale & $\begin{array}{c}0.15 \\
(0.789,0.431)\end{array}$ & $\begin{array}{c}0.23 \\
(0.92,0.359)\end{array}$ & $\begin{array}{c}0.27 \\
(0.871,0.385)\end{array}$ & $\begin{array}{c}0.18 \\
(0.692,0.49)\end{array}$ & $\begin{array}{c}0.18 \\
(0.857,0.393)\end{array}$ & $\begin{array}{c}0.16 \\
(0.593,0.554)\end{array}$ \\
\hline Duration & $\begin{array}{c}0.17 \\
(1.417,0.158)\end{array}$ & $\begin{array}{c}0.11 \\
(0.478,0.633)\end{array}$ & $\begin{array}{c}0.08 \\
(0.471,0.639)\end{array}$ & $\begin{array}{c}0.15 \\
(0.556,0.579)\end{array}$ & $\begin{array}{c}0.14 \\
(0.438,0.662)\end{array}$ & $\begin{array}{c}0.12 \\
(0.387,0.699)\end{array}$ \\
\hline Industry & $\begin{array}{c}-0.13^{*} \\
(-2.167,0.032)\end{array}$ & $\begin{array}{c}0.24 \\
(1.143,0.255)\end{array}$ & $\begin{array}{c}-0.30 \\
(-0.732,0.465)\end{array}$ & $\begin{array}{c}0.27 \\
(0.711,0.478)\end{array}$ & $\begin{array}{c}0.21 \\
(0.7,0.485)\end{array}$ & $\begin{array}{c}0.25 \\
(0.581,0.562)\end{array}$ \\
\hline $\begin{array}{l}\text { Structural } \\
\text { strength }\end{array}$ & & $\begin{array}{c}0.23 \text { * } \\
(2.556,0.012)\end{array}$ & $\begin{array}{c}0.19+ \\
(2.375,0.019)\end{array}$ & $\begin{array}{c}0.11 \\
(0.423,0.673)\end{array}$ & $\begin{array}{c}0.15 \\
(2.143,0.034)\end{array}$ & $\begin{array}{c}0.10 \\
(0.526,0.599)\end{array}$ \\
\hline $\begin{array}{l}\text { Structural } \\
\text { strength }^{2}\end{array}$ & & & $\begin{array}{c}-0.29^{* *} \\
(-2.9,0.004)\end{array}$ & $\begin{array}{c}-0.25 \\
(-0.417,0.677)\end{array}$ & $\begin{array}{c}-0.23 \\
(-1.045,0.297)\end{array}$ & $\begin{array}{c}-0.19 \\
(-0.655,0.513)\end{array}$ \\
\hline $\begin{array}{l}\text { Dependent } \\
\text { asymmetry }\end{array}$ & & & & $\begin{array}{c}-0.07 \\
(-0.233,0.816)\end{array}$ & $\begin{array}{c}-0.06 \\
(-0.75,0.454)\end{array}$ & $\begin{array}{c}-0.09 \\
(-0.429,0.669)\end{array}$ \\
\hline $\begin{array}{l}\text { Structural } \\
\text { strength } \times \\
\text { Dependent } \\
\text { asymmetry }\end{array}$ & & & & & $\begin{array}{c}-0.05+ \\
(-1.917,0.057)\end{array}$ & $\begin{array}{c}-0.03 \\
(-0.103,0.918)\end{array}$ \\
\hline $\begin{array}{l}\text { Structural } \\
\text { strength }^{2} \times \\
\text { Dependent } \\
\text { asymmetry }\end{array}$ & & & & & & $\begin{array}{c}-0.07 \\
(-0.350,0.727)\end{array}$ \\
\hline $\mathrm{R}^{2}$ & 0.15 & 0.21 & 0.23 & 0.23 & 0.25 & 0.26 \\
\hline $\mathrm{R}^{2}$ adjustment & 0.12 & 0.17 & 0.18 & 0.16 & 0.22 & 0.20 \\
\hline$\Delta \mathrm{R}^{2}$ & 0.15 & 0.06 & 0.02 & 0.00 & 0.02 & 0.01 \\
\hline$\Delta \mathrm{F}$ & $4.91^{* *}$ & $0.76^{* *}$ & $0.25 *$ & 0.63 & $0.05+$ & 0.49 \\
\hline $\mathrm{F}$ & & & & & & $4.69 * *$ \\
\hline
\end{tabular}

Note: $\mathrm{N}=\mathrm{I} 66$, the parentheses are ( $\mathrm{t}$ value, $p$ value). $+p<0.10 ;{ }^{*} p<0.05 ;{ }^{* *} p<0.01$

Further, hierarchical regression is used to analyze the regulatory effects of the asymmetry of dependence. In the fourth step of Model 1, the main effects of the asymmetry of dependence are added Table 5 (S4) and the data show that there is no significant correlation between the asymmetry of dependence and risk sharing, meaning that the asymmetry of dependence does not directly affect risk sharing. In the fifth step, the results of S5 show that the interaction between structural strength and the asymmetry of dependence is not significant $(-0.05, p<0.10)$, meaning that the asymmetry of dependence has no significant 
regulatory effect on the relationship between structural strength and risk sharing. In the sixth step, the data of 56 do not show that there is significant interaction between the squared term of the structural strength and the asymmetry of dependence, but they may suggest an inverted $\mathrm{U}$-shaped relationship between risk sharing and relational tie strength, however more empirical evidence is needed to confirm or reject Hypothesis 3 , and in further researches more variables should be included in the analysis.

In Model 2, the first step is to add the control variables Table 6 (S1) to eliminate the influence of the mixed factors. In order to test Hypothesis 2, this paper explores the relationship between tie strength and risk sharing and adds relational strength of tie in the second step of Model 2 to test the main effect of relational strength on risk sharing Table 6 (S2). The results show that there is a significant positive correlation between risk sharing and relational strength, meaning that the higher the level of trust and commitment between trading entities, the less likely the two sides take opportunistic behaviors, which correspondingly reduces the opportunistic risks. At the same time, the two parties adopt equal negotiation and reciprocal behaviors during the transaction process to increase the degree of cooperation between the two parties and to achieve the effect of alleviating or eliminating cooperation risks. Therefore, it plays a positive role in promoting risk sharing. In the third step, the squared term of the relational strength is introduced to reflect the main effect of the square of the relational strength Table 6 (S3). The regression coefficient is $-0.31(p<0.01)$, and the changes of $\mathbf{R}^{2}$ indicate that the explanatory ability of the model is improved to some extent. The linear coefficient of the relational strength is positive, and the data show that there is a significant inverted U-shaped relationship between risk sharing and relational strength of the tie, verifying Hypothesis 2.

Table 6. Hierarchical Regression Analysis.

\begin{tabular}{|c|c|c|c|c|c|c|}
\hline Variables & S1 & $\mathrm{S} 2$ & S3 & S4 & S5 & S6 \\
\hline Enterprise scale & $\begin{array}{c}0.15 \\
(-0.789,0.431)\end{array}$ & $\begin{array}{c}0.12 \\
(-0.8,0.425)\end{array}$ & $\begin{array}{c}0.11 \\
(-0.733,0.464)\end{array}$ & $\begin{array}{c}0.14 \\
(-0.737,0.462)\end{array}$ & $\begin{array}{c}0.15 \\
(-0.682,0.496)\end{array}$ & $\begin{array}{c}0.12 \\
(-0.5,0.618)\end{array}$ \\
\hline Duration & $\begin{array}{c}0.17 \\
(-1.417,0.158)\end{array}$ & $\begin{array}{c}0.25 \\
(-0.806,0.421)\end{array}$ & $\begin{array}{c}0.17 \\
(-0.739,0.461)\end{array}$ & $\begin{array}{c}0.12 \\
(-1.2,0.232)\end{array}$ & $\begin{array}{c}0.11 \\
(-0.478,0.633)\end{array}$ & $\begin{array}{c}0.07 \\
(-0.875,0.383)\end{array}$ \\
\hline Industry & $\begin{array}{c}-0.13^{*} \\
(2.167,0.032)\end{array}$ & $\begin{array}{c}0.31 \\
(-0.756,0.451)\end{array}$ & $\begin{array}{c}-0.36 \\
(0.8,0.425)\end{array}$ & $\begin{array}{c}0.24 \\
(-0.923,0.357)\end{array}$ & $\begin{array}{c}0.25 \\
(-0.862,0.39)\end{array}$ & $\begin{array}{c}0.19 \\
(-0.704,0.483)\end{array}$ \\
\hline $\begin{array}{c}\text { Relational } \\
\text { strength }\end{array}$ & & $\begin{array}{c}0.25 * \\
(-2.016,0.045)\end{array}$ & $\begin{array}{c}0.16+ \\
(-1.778,0.077)\end{array}$ & $\begin{array}{c}0.25 \\
(-1.087,0.279)\end{array}$ & $\begin{array}{c}0.17 \\
(-1.133,0.259)\end{array}$ & $\begin{array}{c}0.19 \\
(-1.462,0.146)\end{array}$ \\
\hline $\begin{array}{l}\text { Relational } \\
\text { strength }^{2}\end{array}$ & & & $\begin{array}{c}-0.31^{* *} \\
(3.275,0.001)\end{array}$ & $\begin{array}{c}-0.33 \\
(0.846,0.399)\end{array}$ & $\begin{array}{c}-0.25 \\
(1.087,0.279)\end{array}$ & $\begin{array}{c}-0.20 \\
(1.25,0.213)\end{array}$ \\
\hline $\begin{array}{l}\text { Dependent } \\
\text { asymmetry }\end{array}$ & & & & $\begin{array}{c}-0.08 \\
(0.889,0.375)\end{array}$ & $\begin{array}{c}-0.10 \\
(1.567,0.119)\end{array}$ & $\begin{array}{c}-0.09 \\
(0.529,0.597)\end{array}$ \\
\hline $\begin{array}{l}\text { Relational } \\
\text { strength } \times \\
\text { Dependent } \\
\text { asymmetry }\end{array}$ & & & & & $\begin{array}{c}-0.07+ \\
(1.7,0.091)\end{array}$ & $\begin{array}{c}-0.05 \\
(1.667,0.098)\end{array}$ \\
\hline $\begin{array}{l}\text { Relational } \\
\text { strength }^{2} \times \\
\text { Dependent } \\
\text { asymmetry }\end{array}$ & & & & & & $\begin{array}{c}-0.19 * * \\
(2.714,0.007)\end{array}$ \\
\hline $\mathrm{R}^{2}$ & 0.15 & 0.35 & 0.37 & 0.37 & 0.40 & 0.42 \\
\hline $\mathrm{R}^{2}$ adjustment & 0.12 & 0.31 & 0.33 & 0.33 & 0.37 & 0.39 \\
\hline$\Delta \mathrm{R}^{2}$ & 0.15 & 0.20 & 0.02 & 0.00 & 0.03 & 0.02 \\
\hline$\Delta \mathrm{F}$ & $4.91^{* *}$ & $4.79 * *$ & $2.14^{*}$ & 1.71 & 0.05 & $0.30 * * *$ \\
\hline $\mathrm{F}$ & & & & & & $5.04^{* *}$ \\
\hline
\end{tabular}

Note: $\mathrm{N}=\mathrm{I} 66$, the parentheses are (t value, $p$ value). $+p<0.10 ;{ }^{*} p<0.05 ;{ }^{* *} p<0.01$; ${ }^{* * *} p<0.001$. 
In the fourth step of Model 2, in order to test the regulatory effect of the asymmetry of dependence, this paper adds variables of the asymmetry of dependence to test its main effect on risk sharing Table 6 (S4). The data show that there is no significant correlation between the asymmetry of dependence and risk sharing; that is, the asymmetry of dependence has no direct influence on risk sharing. The fifth step is to join the interaction term of relational strength and the asymmetry of dependence. The result in Table 6 (S5) shows that the interaction between relational strength and the asymmetry of dependence is not significant $(-0.07, p<0.10)$, meaning that the asymmetry of dependence has no significant regulatory effect on the relationship between relational strength and risk sharing. The sixth step is to join the interaction term of the relational strength and the asymmetry of dependence. Table 6 (S6) shows that the interaction between the square of the relational strength and the asymmetry of dependence is significant $(-0.19, p<0.01)$, indicating that the asymmetry of dependence has a significant regulatory effect on the inverted U-shaped relationship between the relational strength and risk sharing. Hypothesis 4 is verified. Although the changes of $R^{2}$ indicate that the explanatory ability of the model is improved, the more ideal effect is not present, and there may be more variables that have a significant impact on risk sharing that are not taken into account in the model. In the inter-firm relationship network, the resource endowments and enterprise capabilities are heterogeneously distributed, and this heterogeneous distribution effect will be more evident in the supply network. There are only a few core enterprises (manufacturers) in the supply network, which are in a central position in the network, have control power over key resources and have the ability and role to integrate and configure supply network resources. Therefore, in general, upstream suppliers that establish transaction relationships with manufacturers are generally in a relatively weak position, which will affect the suppliers' fairness perception and the subjective utility of the differences in the capabilities and benefits of both parties, ultimately affecting risk-sharing behaviors.

According to Tables 5 and 6, the control variables "enterprise scale" and "relationship duration" have no significant statistical significance, but according to previous research evidence, these variables will have an impact on the explanatory variables. In order to improve the research conclusion, regression is conducted for the main explained variables and explanatory variables. The results are shown in Tables A1 and A2 of Appendix B. The results show that the coefficients of some explanatory variables change, and also, the significance of some explanatory variables change, but none of them have any effect on the empirical results.

\subsection{Further Verification}

In order to further clarify the regulation mode of the asymmetry of dependence, this paper analyzes the different curvatures of inverted U-shaped relation between relational strength and risk sharing under the condition of the symmetry of dependence and the asymmetry of dependence, and performs a simple slope test. The simple slopes are estimated from three different levels of the relational strength. The relational strength of the tie corresponding to the maximum values of the curves are mean values and are divided into the high score group (mean $+1 \mathrm{SD}$ ), the middle group and the low score group (means - 1 SD). The results show that in the case of the asymmetry of dependence, the simple slope of the regression line at the low point of the relational strength is a significant positive value $(b=1.22, t=2.59, p<0.05)$, and the intermediate point simple probability value is not significantly different from zero $(b=-0.04, t=-0.62)$, the simple slope at the high point of the relational strength is significantly negative $(b=-1.21, t=-3.64, p<0.01)$. In contrast, in the case of the symmetry of dependence, the simple slope of the curve is not significantly different from zero for different levels of relational strength. Figure 5 of Appendix $B$ is drawn to reflect the relationship more clearly between relational strength and risk sharing under different dependence asymmetries. 


\section{Discussion and Conclusions}

The existing literature and findings have focused on the impact of tie strength among enterprises on technological innovation and corporate performance, but they do not explicitly discuss the motives and mechanisms of cooperation among manufacturers and suppliers, and do not use the system to construct a theoretical model of the connection relationship among enterprises on the mechanism of risk sharing. A risk-sharing model proposed in this study provides useful theoretical arguments, though which we explore the risk-sharing behavior and mechanism among supply network companies by portraying the tie strength of different types of enterprises. Existing literature may focus on the effect of technological innovation and corporate performance among enterprises, the combination of a strong tie and weak tie, or the effect of the asymmetry of dependence on relation quality. Based on the empirical observations and theoretical studies of existing literature, this paper discusses and defines the dimensions and connotations of the connection relationship among supply network companies, and integrates the theoretical models with risk sharing, tie strength and the asymmetry of dependence. Based on our theoretical arguments and empirical findings, this paper draws the following conclusions.

First of all, there is an inverted U-shaped curve relationship existing between the tie strength of a supply network and risk sharing. This relationship indicates that in the connection relationship among supply network enterprises, it is not just entities' selfinterest motive that will stimulate entities' behaviors, and what is more important-the game structure between upstream and downstream enterprises. Among the enterprises which have the status of heterogeneous resources and interest, an embedded relationship based on trust and reciprocity can promote the formation of long-term company relationship orientation, stimulating resource exchange and optimization combination, which is conducive to establishing stable and effective risk-sharing mechanism. However, if the level of embeddedness is too high, it is hard for new technology and new suppliers to enter, leading to insufficient innovation and reducing suppliers' competitiveness. If things continue in this way, the overall competitiveness of the supply network will also decline. Hence, under the background of uncertainties and limited rationality, manufacturers and suppliers should adjust the embedded relationship during the process of managing upstream and downstream relationships, avoiding behavioral and cognitive biases caused by over-embeddedness and realizing reasonable and effective risk sharing among supply network enterprises.

With regard to moderate embeddedness, in the management practice, compared with the transient and volatile market transaction tie, the embedded relationship-strong tie can stimulate the risk sharing and other cooperation behaviors. Manufacturers establish long-term relationships with key suppliers, and through moderate trust and reciprocity among enterprises, maintain rational decision and improve risk-sharing efficiency. Second, maintaining a moderate interaction frequency and cooperation with the cooperative enterprise, not all resources and information acquisition are dependent on a fixed transaction object which forms an excessive embedded tie, maintains a reasonable tie portfolio and achieves a good competitive cooperation between enterprises.

Second, the empirical results do not support Hypothesis 3. The asymmetry of dependence has no significant regulatory effect on the structural strength of the tie and risk-sharing relationship, which is mainly due to the highly integrated cooperation processes and transaction interface that are formed by manufacturers and suppliers with a strong tie. Even if the relative dependence degree of the two has asymmetrical features, the highly integrated communication and governance model can still form a sustained, stable, and effective risk sharing between the two parties. The resource complementarity of companies with a market transaction tie is low, and the connections are transient and volatile. Both parties realize stable flows of products and raw materials based on contracts through stylized transaction processes and interfaces. In this case, the asymmetry of dependency does not affect the structural strength of enterprise. However, in the manufacturer-supplier relationship, the structural strength of tie is not interfered by the regulation effect of the 
asymmetry of dependence and plays a decisive role on risk sharing. In practice, the design of contracts and the mechanisms of governance are implemented from the perspective of fairness, etc., to ensure the fairness of the process and the distribution, so as to motivate the enterprises to form reliable and predictable behaviors and provide institutional support for the formation of trust in transactions.

Third, the asymmetry of dependence has a significant negative regulatory effect on the relational strength and risk-sharing relationship. In reality, the asymmetry of dependence and the asymmetry of power is a natural existence, which results in influencing the motivation of the subject's trading behavior, reducing relational strength of the tie-trust, reciprocity, and so on. When enterprises make strategic decisions on a relational investment, they are all based on their own rationality and the motivation of pursuing profits, and have comprehensive considerations on the influencing factors of risk sharing-the relational strength of tie, the complementarity of resources, and the equitable distribution of payments, etc. When there are different degrees of relational strength between manufacturers and suppliers, there is also a difference in the regulatory effect of the asymmetry of dependence on the relational strength. As shown in Figure 2, at both ends of the inverted U-shaped curve, the gap between the two curves is the largest, which shows that under different relational strengths, the asymmetry of dependence has different effects on its risk-sharing relationship and under the market transaction tie and over-embedded tie, the regulatory effect of the asymmetry of dependence is particularly significant. Therefore, enterprises should maintain a moderate level of embeddedness, inhibit the regulatory effect of the asymmetry of dependence, and achieve reasonable and effective risk sharing.

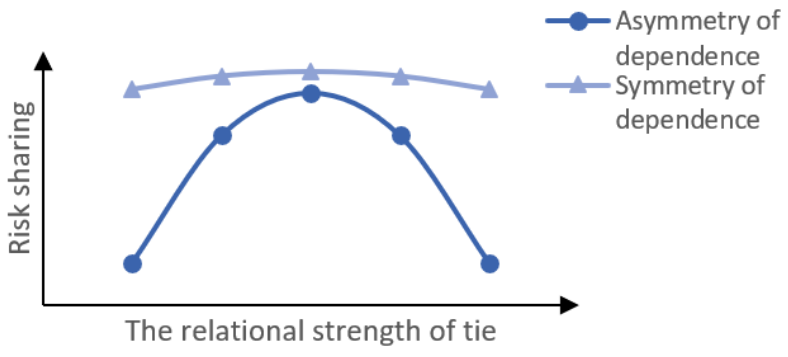

Figure 2. Inverted U-shaped Curve.

Finally, due to the operational difficulty of data collection, the sample data of this paper are mainly from the questionnaire data feedback from suppliers. Although the sample from the manufacturers is cross-checked with the sample data feedback from the corresponding supplier, unilaterally using the supplier's sample data to verify the bilateral relationship between the manufacturers and suppliers may still result in insufficient results and deviations. In future research, data will be further collected from both sides-manufacturers and suppliers-to carry out more in-depth research. Through the research in this paper, however, we also found that there may be more variables that have a significant impact on risk sharing that are not taken into account in the model; therefore, more variables should be included in further researches. In the supply network, how to comprehensively consider the structural strength and relational strength of tie, the asymmetry of the dependence on both parties, and then how to select and design a reasonable governance mechanism to achieve effective risk sharing and improve the performance of the supply chain are not mentioned in this paper, which is also a direction for the research to continue.

Author Contributions: Conceptualization, L.M. and Y.D.; methodology, L.M.; software, L.M.; validation, L.M., Y.D. and M.W.; formal analysis, Y.D.; investigation, L.M.; resources, Y.D.; data curation, L.M.; writing—original draft preparation, L.M.; writing—review and editing, M.W.; visualization, M.W.; supervision, L.M.; project administration, L.M.; funding acquisition, L.M. All authors have read and agreed to the published version of the manuscript. 
Funding: This research was funded by Funds for Cooperative Scientific Research Projects under the Chunhui Plan of the Ministry of Education: "An Empirical Study on the Influence mechanism of China's high-end manufacturing enterprise strategy on Collaborative Innovation Performance from an international perspective: Based on the Innovation ecosystem". This research was funded by Science and Technology Development Project of Jilin Science and Technology Department: "Research on supply chain Financing Risk management of Small and medium-sized technology-based enterprises in Jilin province", grant number: 20190601086FG. This research was funded by National Social Science Fund project: "Research on measurement, driving mechanism and Influence on performance of green entrepreneurship orientation of Agricultural enterprises under rural revitalization Strategy", grant number: 20BGL059.

Institutional Review Board Statement: Not applicable for studies not involving humans or animals.

Informed Consent Statement: Informed consent was obtained from all subjects involved in the study.

Data Availability Statement: The data presented in this study are available on request from the corresponding author.

Conflicts of Interest: The authors declare no conflict of interest.

\section{Appendix A Sample Statistics}

As Figure A1 shows, enterprises are classified into five categories according to their annual sales revenue, with enterprises less than 50 million yuan accounting for $28.3 \%$ of the total sample. The sample as a whole covers enterprises of different sizes, and the data is representative.

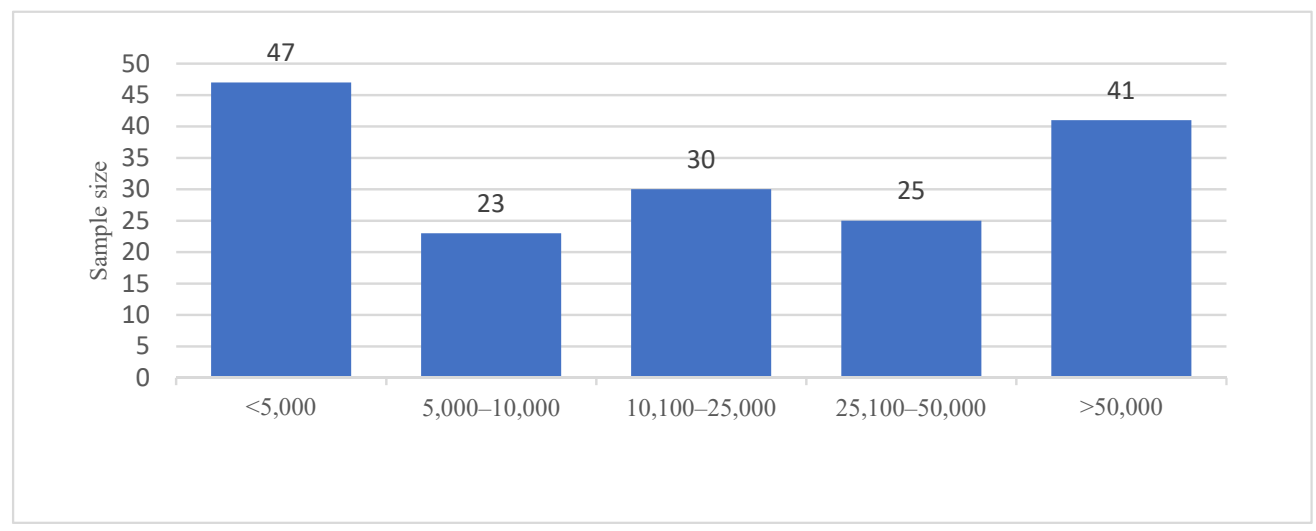

Figure A1. Annual sales revenue.

As Figure A2 shows, enterprises are divided into seven categories according to the number of full-time employees, among which the enterprises with 200 to 500 employees are the most, accounting for $24.7 \%$ of the total sample. Intuitively, the data includes enterprises with different numbers of employees and covers enterprises of different sizes.

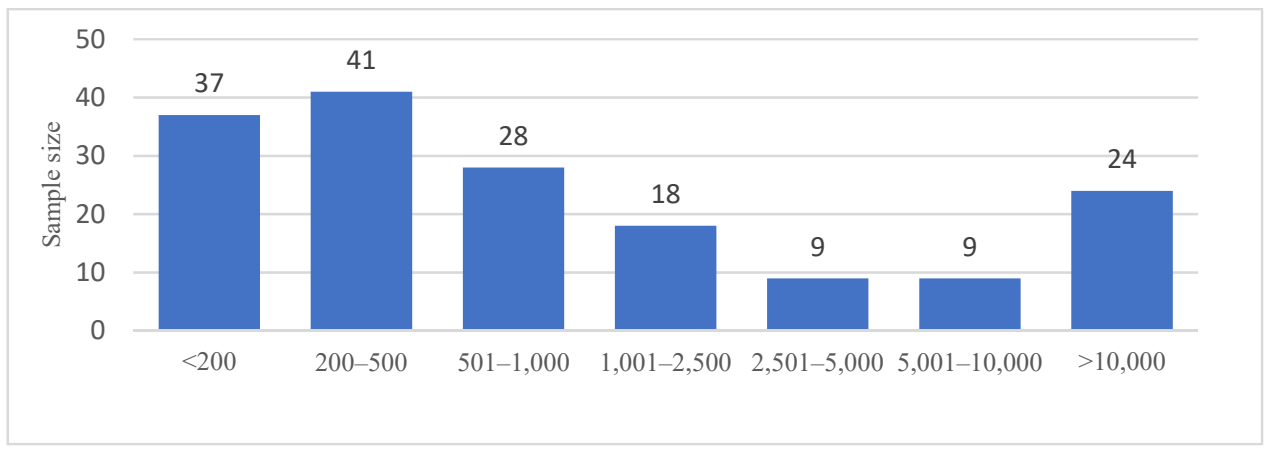

Figure A2. Full-time employees. 
As Figure A3 shows, it is divided into six categories according to the relationship duration, among which the enterprises with relationship duration of 11 to 15 years are the most, accounting for $24.7 \%$ of the sample. The relationship duration is evenly distributed and the data are representative to some extent.

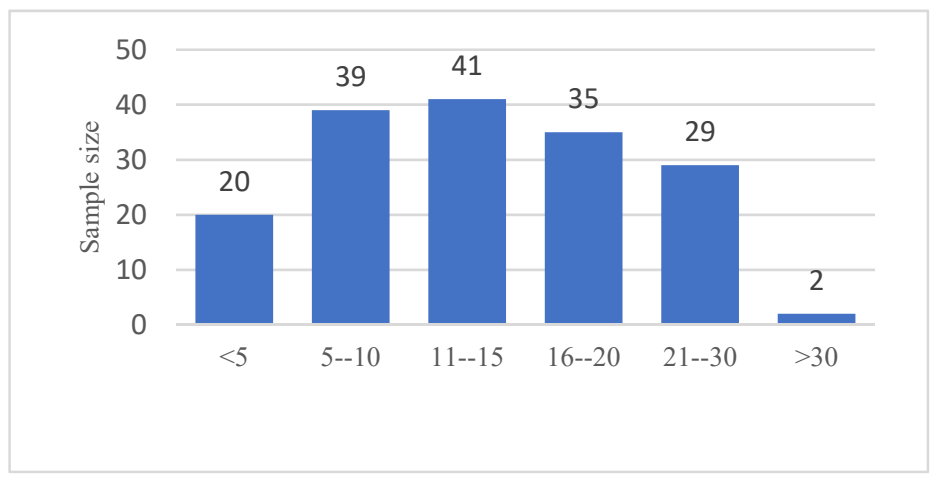

Figure A3. Relationship duration/year.

As Figure A4 shows, the industries of the sample enterprises include auto parts and accessories manufacturing, transportation, automobile repair and maintenance, wholesale (machinery equipment and spare parts), transportation equipment manufacturing, black metal smelting and calendering, plastics and rubber, textiles and leather, etc. Among them, enterprises in the auto parts and accessories manufacturing industry take the largest proportion, accounting for $39.2 \%$ of the total sample. Intuitively, the industries of sample enterprises are evenly distributed.

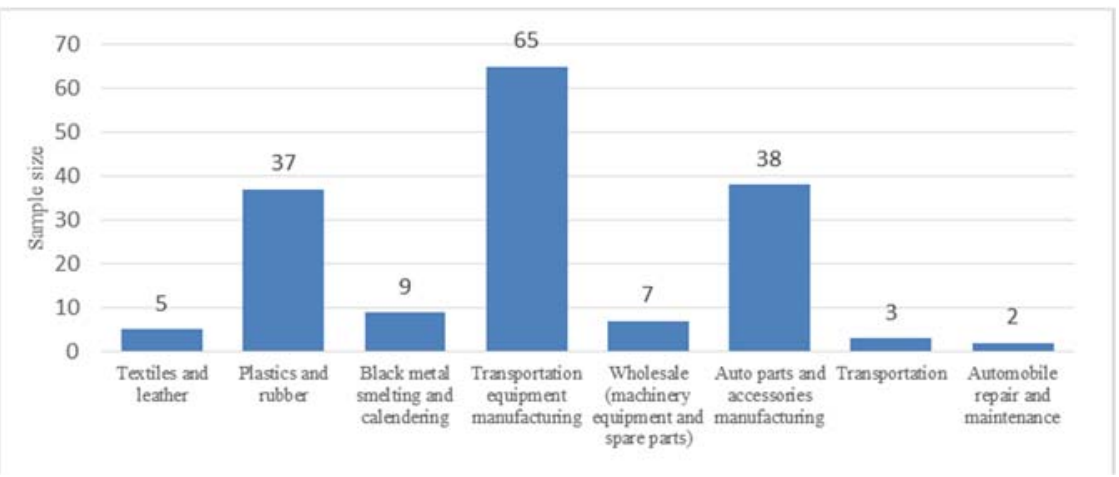

Figure A4. Industry.

The data used in this paper cover enterprises of different annual sales revenue, number of full-time employees, relationship duration and industries. Generally speaking, the data have good representation.

\section{Appendix B}

According to Tables 5 and 6, the control variables "enterprise scale" and "relationship duration" have no significant statistical significance, but according to previous research evidence, these variables will have an impact on the explanatory variables. In order to improve the research conclusion, regression is conducted for the main explained variables and explanatory variables. The results are shown in Tables A1 and A2. The results show that the coefficients of some explanatory variables change, and the significance of some explanatory variables change, but none of them have any effect on the empirical results. 
Table A1. Further description of Model I.

\begin{tabular}{|c|c|c|c|c|c|}
\hline Variables & S2 & S3 & S4 & S5 & S6 \\
\hline Structural strength & $\begin{array}{c}0.54 * * \\
(2.78,0.006)\end{array}$ & $\begin{array}{c}0.44 * \\
(2.01,0.046)\end{array}$ & $\begin{array}{c}0.12 \\
(0.986,0.326)\end{array}$ & $\begin{array}{c}0.23 \\
(2.77,0.006)\end{array}$ & $\begin{array}{c}0.20 \\
(0.72,0.473)\end{array}$ \\
\hline Structural strength ${ }^{2}$ & & $\begin{array}{c}-0.65^{* *} \\
(-3.11,0.002) \\
\end{array}$ & $\begin{array}{c}-0.22 \\
(-0.55,0.583)\end{array}$ & $\begin{array}{c}-0.12 \\
(-1.23,0.22)\end{array}$ & $\begin{array}{c}-0.33 \\
(-0.433,0.666)\end{array}$ \\
\hline Dependent asymmetry & & & $\begin{array}{c}0.03 \\
(-0.433,0.561) \\
\end{array}$ & $\begin{array}{c}0.02 \\
(-0.943,0.826) \\
\end{array}$ & $\begin{array}{c}-0.02 \\
(0.54,0.507)\end{array}$ \\
\hline $\begin{array}{c}\text { Structural strength } \\
\times \text { Dependent asymmetry }\end{array}$ & & & & $\begin{array}{c}-0.10 * * \\
(-1.994,0.048) \\
\end{array}$ & $\begin{array}{c}-0.02 \\
(-0.112,0.911)\end{array}$ \\
\hline $\begin{aligned} & \text { Structural strength } \\
\times & \text { Dependent asymmetry }\end{aligned}$ & & & & & $\begin{array}{c}-0.03 \\
(-0.233,0.816)\end{array}$ \\
\hline Number of samples & 166 & 166 & 166 & 166 & 166 \\
\hline
\end{tabular}

Note: $\mathrm{N}=166$, the standard error is in parentheses. ${ }^{*} p<0.05 ;{ }^{* *} p<0.01$.

Table A2. Further description of Model II.

\begin{tabular}{|c|c|c|c|c|c|}
\hline Variables & S2 & S3 & S4 & S5 & S6 \\
\hline Relational strength & $\begin{array}{c}0.43^{*} \\
(-2.11,0.036)\end{array}$ & $\begin{array}{c}0.21 * \\
(-2.55,0.012)\end{array}$ & $\begin{array}{c}0.22 \\
(-2.1,0.037)\end{array}$ & $\begin{array}{c}0.14 \\
(-2.12,0.036)\end{array}$ & $\begin{array}{c}0.14 \\
(-1.32,0.189)\end{array}$ \\
\hline Relational strength ${ }^{2}$ & & $\begin{array}{c}-0.12 * * \\
(3.2,0.002)\end{array}$ & $\begin{array}{c}-0.55 \\
(-1.2,0.232)\end{array}$ & $\begin{array}{c}-0.31+ \\
(-1.88,0.062)\end{array}$ & $\begin{array}{c}-0.31 \\
(2.32,0.022)\end{array}$ \\
\hline Dependent asymmetry & & & $\begin{array}{c}-0.01 \\
(0.13,0.817)\end{array}$ & $\begin{array}{c}0.3 \\
(-0.75,0.951)\end{array}$ & $\begin{array}{c}-0.12 \\
(-0.41,0.983)\end{array}$ \\
\hline $\begin{array}{c}\text { Relational strength } \\
\times \text { Dependent asymmetry }\end{array}$ & & & & $\begin{array}{c}-0.1+ \\
(-1.95,0.053)\end{array}$ & $\begin{array}{c}-0.04 \\
(1.77,0.079)\end{array}$ \\
\hline $\begin{aligned} & \text { Relational strength }^{2} \\
\times & \text { Dependent asymmetry }\end{aligned}$ & & & & & $\begin{array}{c}-0.33 \text { ** } \\
(3.12,0.002)\end{array}$ \\
\hline Number of samples & 166 & 166 & 166 & 166 & 166 \\
\hline
\end{tabular}

Note: $\mathrm{N}=166$, the standard error is in parentheses. $+p<0.10 ;{ }^{*} p<0.05 ;{ }^{* *} p<0.01$.
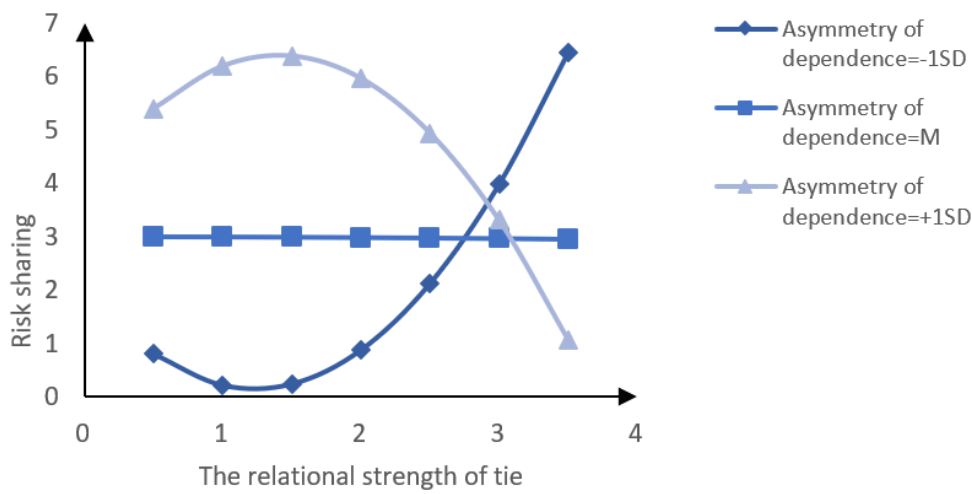

Figure 5. The adjustment function of the asymmetry of dependence. 


\section{References}

1. Nat, F. Risk, Uncertainty and Profit, 1st ed.; Commercial Press: Shanghai, China, 2010; pp. 24-31.

2. Wu, J.; Li, J.; Wang, S.Y. Several important issues in supply chain risk management. J. Manag. Sci. 2006, 6, 71-85.

3. Xu, D.H.; Li, G.; Zhao, L. The relationship among environmental uncertainty, supply chain integration and firm performance. Sci. Res. Manag. 2012, 12, 65-81.

4. Williamson, O. Economics of Transaction Cost: Regulation of Contractual Relationship, 1st ed.; Shanghai Sanlian Bookstore: Shanghai, China, 1966; pp. 300-320.

5. Chen, H.Z.; Fang, Z.; Liu, S.F.; He, L.F. The optimal cost-sharing incentive strategy of main manufacturer-suppliers for complex product. Chin. Manag. Sci. 2014, 27, 131-141.

6. Claycomb, C.; Frankwick, G. Buyer's perspectives of buyer-seller relationship development. Ind. Mark. Manag. 2010, 39, 252-263. [CrossRef]

7. Camuffo, A.; Furlan, A.; Rettore, E. Risk sharing in supplier relations: An agency model for the Italian air conditioning industry. Strateg. Manag. J. 2007, 28, 1257-1266. [CrossRef]

8. Zhao, X.L.; Qi, J.X. Research on cooperative benefit distribution mechanism under different cooperation modes of supply chain-take the supply chain of coal power enterprises as an example. Chin. J. Manag. Sci. 2007, 37, 1109-1120.

9. Tang, C.; Sodhi, M. Managing Supply Chain Risk; Springer: Berlin/Heidelberg, Germany, 2012.

10. Peng, H.J.; Zhou, M.H.; Liu, M.L. Research on risk sharing model in supply chain with uncertainties in two-level yields and demand. J. Ind. Eng. Eng. Manag. 2013, 29, 131-142.

11. Chen, X.G.; Yu, H.; Fan, L.J. Oversea embedded feature, knowledge search and innovation performance of the research and development team-empirical study based on Zhejiang high-tech enterprises. Stud. Sci. Sci. 2010, 10, 71-91.

12. Du, Y.L.; Yin, H. The Influence of social capital on proper risk allocation in construction projects. J. Ind. Eng. Eng. Manag. 2015, 15, 221-241.

13. Kim, Y.; Choi, T.Y. Deep, sticky, transient and gracious: An expanded buyer-supplier relationship typology. J. Supply Chain Manag. 2015, 51, 61-86. [CrossRef]

14. Uzzi, B. Social structure and competition in inter-firm networks: The paradox of embeddedness. Adm. Sci. Q. 1997, 42, 35-67. [CrossRef]

15. Wang, S.Q.; Wang, D.; Wu, L.D. The internal mechanism in which the network of the relationship between the parent company and its subsidiary impacts on the subsidiary starting an undertaking: A case study based on the Hisense group. Manag. World 2012, 13, 98-110.

16. Uzzi, B. The sources and consequences of embeddedness for the economic performance of organizations: The network effect. Am. Soc. Rev. 1996, 61, 674-698. [CrossRef]

17. Yang, Z.N.; Li, H.D.; Fan, L.B. Trapped in a "spiral of silk": Over-embedded social network relationship has affected the entrepreneurial process? Manag. World 2013, 12, 87-96.

18. Touboulic, A.; Chicksand, D.; Walker, H. Managing imbalanced supply chain relationships for sustainability: A power perspective. Decis. Sci. 2014, 45, 577-619. [CrossRef]

19. Wong, C.; Boon, S. The influence of institutional norms and environmental uncertainty on supply chain integration in the Thai automotive industry. Int. J. Prod. Econ. 2008, 115, 400-410. [CrossRef]

20. Hoetker, G. Choice and performance of governance mechanisms. Strateg. Manag. J. 2009, 30, 1025-1044. [CrossRef]

21. Krackhardt, D. The Strength of Strong Ties: The Importance of Philosophy in Organizations. Netw. Organ. 1992, 216-239. [CrossRef]

22. Eisenhardt, K.; Schoonhoven, C. Resource-based view of strategic alliance formation: Strategic and social effects in entrepreneurial firms. Organ. Sci. 1996, 7, 136-150. [CrossRef]

23. Zollo, M.; Reuer, J.; Singh, H. Inter-organizational routines and performance in strategic alliances. Organ. Sci. 2002, 13, 701-713. [CrossRef]

24. Hansen, M. The search-transfer problem: The role of weak ties in sharing knowledge across organization subunits. Adm. Sci. $Q$. 1999, 44, 82-111. [CrossRef]

25. Lin, Q. Research on the Relationship Between Network Embeddedness, Dynamic Capabilities and Collaborative Innovation Performance of Supply Chain; South China University of Technology: Guangzhou, China, 2019.

26. Astley, W.; Zajac, E. Beyond dyadic exchange: Functional interdependence and subunit power. Organ. Stud. 1990, 11, 481-501. [CrossRef]

27. Granovetter, M.S. The strength of weak ties. Am. J. Soc. 1973, 78, 1360-1380. [CrossRef]

28. Du, Y.L.; Li, H.L.; Tong, P.; Yin, Y.L. Initial trust, flexible contract and project management performance: An empirical study on the intermediary model. Manag. Rev. 2015, 25, 231-253.

29. Stanko, M.A.; Bonner, J.; Calantone, R. Building commitment in buyer-seller relationships: A tie strength perspective. Ind. Mark. Manag. 2007, 36, 1094-1103. [CrossRef]

30. Mcevily, B.; Marcus, A. Embedded ties and the acquisition of competitive capabilities. Strateg. Manag. J. 2005, 26, 1033-1055. [CrossRef]

31. Schumpeter, J. Theory of Economic Development: An Inquiry into Profits, Capital, Credit, Interest and the Business Cycle; Harvard University Press: Cambridge, MA, USA, 1934. 
32. Gunasekaran, A.; Lai, K.; Cheng, T. Responsive supply chain: A competitive strategy in a networked economy. Omega 2008, 36, 549-564. [CrossRef]

33. Gadde, L.; Snehota, I. Making the most of supplier relationships. Ind. Mark. Manag. 2000, 29, 305-316. [CrossRef]

34. Chu, Y.Q.; Tian, X.; Wang, W.Y. Corporate innovation along the supply chain. Manag. Sci. 2018, 25, 215-230. [CrossRef]

35. Sanjeev, Y.; Sunil, L.; Dixit, G. Internet of things (IoT) based coordination system in Agri-food supply chain: Development of an efficient framework using Dematel-Ism. Oper. Manag. Res. 2020, 1-27, Prepublish. [CrossRef]

36. Anand, N.; Constantin, B.; Choi, Y.; Lee, G. Re-visiting collaborative behavior in supply networks-structural embeddedness and the influence of contextual changes and sanctions. J. Purch. Supply Manag. 2018, 24, 135-150.

37. Villena, V.; Revilla, E.; Choi, T. The dark side of buyer-supplier relationships: A social capital perspective. J. Oper. Manag. 2011, 29, 561-576. [CrossRef]

38. Lechner, C.; Frankenberger, K.; Floyd, S. Task contingencies in the curvilinear relationships between intergroup networks and initiative performance. Acad. Manag. J. 2010, 53, 865-889. [CrossRef]

39. Liu, X.; Chen, J.J. Network connection, inter-organizational learning and industrial cluster capacity improvement-empirical study based on Zhejiang. Stud. Sci. Sci. 2011, 89, 290-330.

40. Coleman, J. Social capital in the creation of human capital. Am. J. Soc. 1988, 94, 95-120. [CrossRef]

41. Johnston, D.; Mccutcheon, D.; Stuart, F.; Kerwood, H. Effects of supplier trust on performance of cooperative supplier relationships. J. Oper. Manag. 2004, 22, 23-38. [CrossRef]

42. Sarkar, M.; Echambadi, R.; Cavusgil, S.; Aulakh, P. The influence of complementarity, compatibility and relation capital on alliance performance. J. Acad. Mark. Sci. 2001, 29, 358-373. [CrossRef]

43. Hagedoorn, J.; Frankort, H. The gloomy side of embeddedness: The effects of overembeddedness on inter-firm partnership formation. Adv. Strateg. Manag. 2008, 25, 503-530.

44. Artur, S. Manufacturer structural embeddedness and the network rent: The intervening role of relational embeddedness in the triadic supply chains. Supply Chain Manag. Int. J. 2019, 24, 180-200.

45. Li, D.; Yang, J. The effect of dual relational embeddedness and trust on alliance governance. Corp. Gov. Int. J. Bus. Soc. 2017, 17, 913-926. [CrossRef]

46. Adenike, A.M. Understanding supply chain collaboration and risk management. Int. J. Risk Conting. Manag. 2018, 7, 124-139.

47. Jong, B.; Elfring, T. How does trust affect the performance of ongoing teams? The mediating role of reflexivity, monitoring and effort. Acad. Manag. J. 2014, 53, 535-549. [CrossRef]

48. Novak, T.; Hofman, D.; Duhachek, A. The influence of goal-directed and experiential activities on online flow experiences. J. Consum. Psychol. 2003, 3, 3-16. [CrossRef]

49. Wuebker, R.; Hampl, N.; Wiistenhagen, R. The strength of strong ties in an emerging industry: Experimental evidence of the effects of status hierarchies and personal ties in venture capitalist decision making. Strateg. Entrep. J. 2015, 9, 167-187. [CrossRef]

50. Wu, G.; Ding, J.; Chen, P. The effects of GSCM drivers and institutional pressures on GSCM practices in Taiwan's textile and apparel industry. Int. J. Prod. Econ. 2012, 135, 618-636. [CrossRef]

51. Molina-Morales, F.; Marttnez-FernOndez, M. Too much love in the neighborhood can hurt: How an excess of intensity and trust in relationships may produce negative effects on firms. Strateg. Manag. J. 2009, 30, 1013-1023. [CrossRef]

52. Yli-Renko, H.; Autio, E.; Sapienza, H. Social capital, knowledge acquisition, and knowledge exploitation in young technologybased firms. Strateg. Manag. J. 2001, 22, 587-613. [CrossRef]

53. Granovetter, M. Economic action and social structure: The problem of embeddedness. Am. J. Soc. 1985, 91, 481-510. [CrossRef]

54. Anderson, E.; Jap, S. The dark side of close relationships. MIT Sloan Manag. Rev. 2005, 46, 75-82.

55. Zhang, Q.; Sheng, S.; Zhou, K. Are relational ties always good for knowledge acquisition? Buyer-supplier exchanges in China. J. Oper. Manag. 2014, 32, 88-98. [CrossRef]

56. Bendoly, E.; Croson, R.; Goncalves, P.; Schuhz, K. Bodies of knowledge for research in behavioral operations. Prod. Oper. Manag. 2010, 19, 434-452. [CrossRef]

57. Dome, M.M.; Prusty, S. Critical analysis of factors impacting trust and opportunism in Agri-food supply chains: The case of tomato in the Northern Tanzania. Int. J. Bus. Process Integr. Manag. 2020, 9, 267-280. [CrossRef]

58. Bendoly, E.; Swink, M. Moderating effects of information access on project management behavior, performance and perceptions. J. Oper. Manag. 2007, 25, 604-622. [CrossRef]

59. Pangarkar, A.M. Strategic alignment: Linking your learning strategy to the balanced scorecard. Ind. Commer. Train. 2008, 40, 95-100. [CrossRef]

60. Gulati, R.; Sytch, M. Dependence asymmetry and joint dependence in interorganizational relationships: Effects of embeddedness on a manufacturer's performance in procurement relationships. Adm. Sci. Q. 2007, 52, 32-69. [CrossRef]

61. Chen, J.; Yang, Y.J. Theoretical basis and content for collaborative innovation. Stud. Sci. Sci. 2012, 12, 37-48.

62. Mitsuhashi, H.; Greve, H. A matching theory of alliance formation and organizational success: Complementarity and compatibility. Acad. Manag. J. 2008, 52, 975-995. [CrossRef]

63. Wu, Z.; Choi, T. Supplier-supplier relationships in the buyer-supplier triad: Building theories from eight case studies. J. Oper. Manag. 2005, 24, 27-52. [CrossRef]

64. Sun, X.Y. Asymmetric Dependence, Perceived Fairness and Relationship Risk; Shanxi Finance University: Taiyuan, China, 2018. 
65. Zirpoli, F.; Caputo, M. The nature of buyer-supplier relationships in co-design activities: The Italian auto industry case. Int. J. Oper. Prod. Manag. 2013, 22, 1389-1410. [CrossRef]

66. Cox, A. Transactions, power and contested exchange: Towards a theory of exchange in business relationships. Int. J. Procure. Manag. 2007, 1, 38-59. [CrossRef]

67. Keltner, D.; Robinson, R. Defending the status quo: Power and bias in social conflict. Pers. Soc. Psychol. Bull. 1997, 23, 1066-1077. [CrossRef]

68. Lawler, E.; Yoon, J. Commitment in exchange relations: Test of a theory of relational cohesion. Am. Soc. Rev. 1996, 61, 89-108. [CrossRef]

69. Liu, B.H. Procurement and Supply Chain Management: A Practitioner's Perspective, 1st ed.; China Machine Press: Beijing, China, 2015; pp. 128-130.

70. Emerson, R. Power dependence relations. Am. Soc. Rev. 1962, 27, 31-41. [CrossRef]

71. Poppo, L.; Zhou, K. Managing contracts for fairness in buyer-supplier exchanges. Strateg. Manag. J. 2014, 35, 1508-1527. [CrossRef]

72. Africa, A.; Smith, R. The role of fairness in alliance formation. Strateg. Manag. J. 2010, 31, 1054-1087.

73. Covin, J.; Slevin, D. A conceptual model of entrepreneurship as firm behavior. Entrepre. Theory Pract. 1991, 16, 7-25. [CrossRef]

74. Ren, X.Y.; An, J.L.; Qian, L.P. Does interdependence asymmetry always jeopardize relationship quality? Manag. World 2009, 27,31-41.

75. Kumar, N.; Scheer, L.; Steenkamp, E. The effects of perceived interdependence on dealer attitudes. J. Mark. Res. 1995, 32, 348-356. [CrossRef]

76. Ireland, R.; Webb, J. A multi-theoretic perspective on trust and power in strategic supply chains. J. Oper. Manag. 2007, 25, 482-497. [CrossRef] 